\title{
Ability Based Transformation and Reconstruction of Teachers' Roles
}

\author{
Liwei SUN \\ School of Foreign Languages(International Communication) \\ Jilin Agricultural Science and Technology University, \\ Jilin, China
}

\begin{abstract}
Under the background of big data and information technology, The issue of how to develop higher education to fit the need of the Belt and Road national strategy and How college English education should make the most use of this background to cultivate international English talents and Great county craftsmen are becoming heated topics. College English Teacher, a key element of college English education, plays an indispensable role in college English teaching. Therefore, the paper holds that college English teachers should reconsider and reflect their roles in college English te aching and changing and reconstructing their roles from teachers to designers, coaches, directors and tour guides on the basis of cultivating students' abilities including their English application ability, self-study ability, life-learning ability, communication ability and so on. Besides, an empirical study has been conducted, which gives a positive feedback to the changing of teachers' roles.
\end{abstract}

Keywords-Ability Based; College Teachers' Roles; Changes; Transformation; Reconstruction

\section{INTRODUCTION}

China's $19^{\text {th }}$ National Congress of the Communist Party has witnessed the promotion of the spirit of labor model and craftsmanship. Meanwhile, the development of vocational education has been equally emphasized. Therefore, there is an urgent need to integrate craftsman spirit with education and teaching. The director of the Minister of Education of China, Chen Baosheng has put forward the concept of cultivating technical talents with the joint effort of vocational education and higher education.(Chen Baosheng, 2018) College English education is an indispensable part of China's higher education system, which plays a significant role in the coordinated development of students' knowledge and comprehensive abilities. College English education in China plays the functions of the cultivation of students English application ability and promoting students' comprehensive ability, all of which will contribute to the transmission of Chinese culture. Thus, how to cultivate students' English application ability through English teaching has become an important mission for College English teaching in the new era, which will in turn be beneficial to more students.

Enabling students to possess the craftsman spirit is to equip students with all the abilities and qualities that a craftsman should have. As for the course of English, it contains the cultivation of students English skills such as listening, speaking, reading, writing and translation and those abilities derived from the acquisition of those skills, such as the abilities of selflearning, communication and coordination, logical analysis, cross cultural communication, creation and critical thinking ability and so on, all of which will lay a solid foundation for students to possess the craftsman spirit. Therefore, how to equip students with those abilities becomes a key issue to discuss. One of the most important solutions might lie in the teacher. According to the "National Medium and Long Term Educational Reform and Development Program(2010-2020), teacher plays a decisive role in education. Whether a student will possess the craftsman spirit depends on how teachers cultivate and educate them. College English teachers in this new era play an essential role in equipping students with various comprehensive abilities. And English course is just a bridge to connect teachers and students. Therefore, it is necessary to transform and reconstruct teachers' roles in order to cultivate students’ comprehensive ability.

\section{The Current State of Teachers' Roles at College}

A survey has been conducted on the issue of English teachers' roles in five universities within Jilin Province. Abundant data have been collected through telephone, interview and questionnaire. The current state of teachers roles are analyzed based on the collected data. First of all, under the background of big-data, multimedia and new media, Teacher centered classroom teaching is still permeated in classroom English teaching. Students seldom speak, though occasionally, are forced and passive. There is not any sign of students' active participation in classroom learning according to classroom observation. Such phenomena are due to two reasons, firstly, the deduction of English learning hours in most universities make the teachers have no time to communicate with students in order to finish their teaching task within a limited time. Second, Most students are from the countryside in some universities, their English level is not proficient enough to participate in classroom activities. Over time, Teacher-centered classroom has become a routine. According to the analysis of the survey result, 30\% students think they could accept teachercentered classroom for the reason that such classroom is energy saving and relaxed. However, 70\% students hold the opinion that teacher-centered classroom do harm to their long term development and their English learning confidence and interests have been hindered and their abilities have not been fostered. 
Second, according to classroom observation, it is found that multimedia has been applied widely in more universities; however, this equipment is only utilized to fill students with knowledge rather than cultivating their ability. Besides, Despite some universities has implemented new teaching methods like flipped classroom, their understanding about it is not that sufficient. For instance, some classroom has been solely "student-centered", Teachers give absolute authority to students and ask them to do presentations and report in classroom. In this case, the role of teachers is audience. The problem in such classroom is that teacher doesn't guide students and comment on their performances, which will be not beneficial for students to learn new things. According to the result of the survey, there still exists the phenomenon of emphasizing knowledge transmission while weakening their ability transmission. In the era of Information technology, new teaching model and concept has been emerging constantly, it is worth to exploring teachers' new roles based on cultivating of students' ability.

\section{Ability Based Transformation and Reconstruction OF TEACHERS’ ROLES}

Based on the above mentioned state of college English teachers, it seems that the transformation and reconstruction of teachers' roles is extremely necessary for the sake of cultivating students' ability and embody teachers with the spirit of craftsmanship. The several of strategies have been put forward which will give some insights on the transformation of college teachers' roles in classroom English teaching. Teachers, in this new era should be generalists who are able to play a variety of different roles. The roles of teachers should be transferred to designers, coaches, directors and tour guides and each of which will be illustrated in the following parts.

\section{A. From Teacher to Designers}

Whether an English classroom is excellent or not depends on the wisdom design of teachers, through which an effective communication can be achieved. The design of teachers will be just like bridges which connect both the teachers and students effectively. Students' ability could be practiced through teachers elegant design. Thus, it requires the changing of teachers' roles to designers and well prepared designers. Teachers should design every classroom teaching procedures including the choices of teaching contents, the difficulties and the importance; even the procedure of lead in and the transition of each step should be designed carefully. In each class, the choice of exercises, activities, homework and evaluation process should also be considered delicately. The choice of teaching method should be put in a higher priority. The changing of teachers roles requires teachers to make the most use of every effective method and the integration of each one. Here, task-based approach should be highly recommended for the reason that in the process of designing each task, the role of teachers has been transferred to be designers unconsciously.

First, English class should be designed based on which type the class belongs to, a listening class or a writing one, a reading class or a translation one. Different classroom activities are designed based on the characteristics of the class type. For instance, various pictures, PPT, cards and multimedia are to be designed to stimulate students' expression and application ability in a listening class. Besides, a variety of tasks should be designed in the reading class in order to cultivate students' cognitive skills and critical thinking ability. Specifically, the task of transferring from direct speech to indirect speech, the task of matching and retelling stories could be designed while reading; Group activities, pair work should be designed in the translation class; the model of flipped classroom can be designed in writing class in which the evaluation and appreciation of students work could be done in class and the writing assignment could be finished before class. In addition, question asking process should be designed according to students' English level and their English basis. Each student should be paid attention to in order to encourage their English learning confidence. What is more, drills and exercises should also be designed, adapted, added and deleted based on the cultivation of students' ability. Last, the content of the blackboard and PPT should also be concise and brief in order to make the target students concentrate on what the teachers has input.

\section{B. From Teachers to Coaches}

Compared with teachers, one to one relationship is emphasized for coaches. This relationship could be realized between teacher and students under the background of fewer students. The mentor system has been set up in most universities. Mentors are like personal coaches, who will guide students' study and life patiently. Therefore, if teachers play the same role as a coach, who will accompany each student as a companion, guide as a partner in the process of students' development, all kinds of students' abilities will be enhanced. In this relationship, teacher and students coordinate with each other in their learning and teaching process. Teachers could satisfy students' requirement by observing and listening. For instance, a typical study curriculum or plan should be tailored based on the students' needs. What is more, with the guide of the teacher, some professional training could also be offered more specifically to broaden students learning resources. In the process of transform, students' problem solving ability could be improved with the caring guidance of a coach.

To be specific, a personalized file could be prepared for each student to record their learning process. In each file, a learning objective, learning process, evaluation process should be recorded. In this process, teacher appears as a partner and cooperator, which shorten their distance with students. Besides, students could be selected to assist teachers to track the files. Videos and other learning evidence are kept in the file during the whole semester. Teachers are going to evaluate students' progress by taking this personal file into important consideration. After teachers transformation, students are able to discover and solve their own problems, and other relevant abilities are also cultivated. Teachers could assist students based on the result of the file and guide them one by one. A mutual respect relationship is set up during the process, which is the source and power of students process of self- enrichment.

\section{From Teachers to Directors}

To solve the problem of emphasizing the teaching of reading and writing while weakening the teaching of listening 
and speaking, the role of teachers could also be transferred to be a director just like a movie director especially in the teaching of listening and speaking. Teachers could instruct students as a director instructs his actors. In English learning, students should be required to listen to more English materials and watch English movies after class in order to have a direct input. In class activities, students are required to do short plays that they have practiced after class in order to demonstrate and practice their English speaking ability. The task of doing a play could be assigned at the beginning of this semester; students could do the task of role play as an interest rather than an assignment. Each student's participation is encouraged and the more students are engaged in the activity, the better. The topic of the play could be vary from classical English stories as Cinderella, Snow White and Seven dwarfs to Chinese traditional classics as Journey to the West. The choice of an actor or actress could be tailored according to students' English level. Students in any proficiency level could be engaged in the activity through which their confidence, communication ability and cooperative spirit could also be promoted. What is more, through the repeated rehearsal, students' fear of speaking in front of the audiences could also be overcome. All of these abilities can not be easily achieved through traditional English classroom study. Students could present their performances annually in the school's yearly English event or activities. Though the process of practicing is extremely difficult, the feeling of satisfaction can not be matched by any other forms of learning and practice.

\section{From Teachers to Tour Guide}

College English is essential for the acquisition of foreign language and culture and the transmission of Chinese culture. However, traditional teachers roles are not completely suitable for the cultivation of students application ability. Therefore, the roles of teachers could be transferred to be a tour guide under which circumstance students are changed into tourists. With the guide of a tourist, teacher in English classroom teaching, students who are involved in could experience foreign culture thoroughly.(M.Young, 2012) Specifically, teachers could cooperate with the tour guides in a travel company and a tour guide could be invited to the classroom directly to teach students, especially those who have the experiences of visiting foreign countries frequently. A virtual scene could be appeared in classroom, where students are led by the teacher to experience foreign culture directly. What is more, students themselves could transform to be a tour guide, who will lead their classmates to enjoy the scenery of their hometown. Through the changing of teachers roles and the simulation of the real travel scene, students' motivation and interests could be enhanced.

\section{The empirical Study of the Changing of Teachers ROLES}

In order to verify the effects of teachers role changes in classroom teaching, two classes have been selected as the experimental group and the controlled group. The two sample classes equal in the number of students and gender. What is more, the proportion of the sources of these students is also similar. The participates' English level is more or less similar through the English test before the experiment. The detailed information about participates can be illustrated in the following table.

TABLE I. THE COMPARISON OF THE PARTICIPANTS

\begin{tabular}{|c|c|c|c|c|}
\hline Group & $\mathrm{N}$ & Sources & Boys & Girls \\
\hline Experiment & 63 & $\begin{array}{c}\text { City:22\% } \\
\text { Country:78\% }\end{array}$ & $46 \%$ & $54 \%$ \\
\hline Controlled & 62 & $\begin{array}{c}\text { City:24\% } \\
\text { Country:76\% }\end{array}$ & $42 \%$ & $58 \%$ \\
\hline
\end{tabular}

From the above table, it can be seen that the experiment is fair for the participants, which will be justifiable to explain the results of the empirical research.

This research is a combination of both quantitative and qualitative research, four methods are employed in order to collect data, and they are questionnaire, survey, classroom observation and classroom experiment. First of all, the questionnaires have been distributed in order to investigate the effectiveness of the changing roles of teachers among the experimental groups after the implementation of teachers new roles in classrooms, the survey of their attitude towards the changing role of teachers can be demonstrated in the following table.

TABLE II. STUDENT S’ ATt ATUDE TOWARDS THE CHANGING ROLES OF TEACHERS

\begin{tabular}{|l|l|l|}
\hline Results & N & SD \\
\hline Reasonable & 97 & $82 \%$ \\
\hline Unreasonable & 3 & $18 \%$ \\
\hline \multicolumn{2}{|c|}{ (NOTES: N=number, SD=Std.) } \\
\hline
\end{tabular}

From the above table, it can be seen that the number of students who are satisfied with the changing of teachers' roles in classroom obviously outweigh that of those who are not satisfied. Through the analysis of the survey results and with the combination of the questionnaire results, it can be analyzed that most of the students are having a higher expectation on teachers and they expect to reap more from the design of teachers and they are hoping to have an English class with the role changes of the teachers and new roles for themselves and in the newly constructed atmosphere their relevant English abilities will also be cultivated through the transformation of teachers' roles.

In the investigation of students learning effects, both the controlled class and the experiment class are using the same listening and speaking materials. However, the roles of teachers are totally different between the two. In the controlled group, teacher teaches the teaching materials by using the traditional method and in the experiment group, teachers change their roles based on different class types, which give students a brand new experiences. And formative and summative assessment is involved in the evaluation of students learning effects. Formative assessment is more emphasized on the assessment of students learning effects. After the transformation of teachers' roles, students listening ability has been greatly improved. After the analysis of the test results between the controlled group and the experiment group through SPSS13.0, the mean score of the experiment group has been improved from 39.12 to 44.30 as can be seen from the 
following table. From the result of the pretest and post-test, students' ability in listening and speaking has been dramatically enhanced. The results of the test can be embodied in the following tables.

TABLE III. PRETEST RESULTS OF THE EXPERIMENTAL GROUP IN LISTENING

\begin{tabular}{|l|l|l|l|l|l|}
\hline $\mathrm{N}$ & Minimum & Maximum & Mean & Std.Deviation & Std. Error Mean \\
\hline 55 & 30.0 & 48.0 & 39.25 & 1.99 & 0.78 \\
\hline
\end{tabular}

TABLE IV. POST-TEST RESULTS OF THE EXPERIMENTAL GROUP IN LISTENING

\begin{tabular}{|l|l|l|l|l|l|}
\hline $\mathrm{N}$ & Minimum & Maximum & Mean & Std.Deviation & Std.Error Mean \\
\hline 55 & 36.0 & 50.0 & 43.25 & 2.19 & 0.34 \\
\hline
\end{tabular}

From the above table, it can be concluded that with the changing of teachers' roles, students' listening ability is much better than before. Students' mean level of listening ability has been enhanced. Similar results can also be found in the assessment of students' speaking test. Besides, through the interview with students one by one, the students in the experiment group demonstrate a high motivation in English learning. They prefer the teacher's new roles as well as their own. Through the active participation in classroom learning, students feel that they are the center of the whole classroom and their organized, cooperative, and autonomous learning ability has been cultivated in the process of learning. Besides, teachers are more accustomed to their new roles and they feel proud for the achievements of students though the transformation and construction of their roles requires them more efforts than before. Everything is worthwhile when teachers see their hard work paid off.

\section{CONCLUSION}

This paper demonstrates the strategies of teachers role transformation from teachers to designers, coaches, directors and tour guides, and with the help of empirical study, it concludes that with the role changes, students' listening and speaking ability could be finally improved. Some problems are existed in the research of this paper, firstly, the questionnaire is only confined to the students within Jilin Province, which makes the collected data may not reflect the phenomena in the whole country. Besides, the empirical study of only one semester may not fully verify the effectiveness of the learning results. What is more, teachers attitude towards their new roles and their adaption to the new roles have not been surveyed, which will be studied in the further research about teachers' roles.

In the preface of a book by Jacques Delors, "Learning: The Treasure Within”, the writer mentions that any form of reform can't be succeed without the active participation of teachers.(Delors, 2001) The important position of a teacher illustrates the necessity of changing the role of teachers. With the rapid development of education, the role of teachers should be strengthened rather than being weakened, and it is more important than any other time in the new era. Teachers should be a generalist who is able to design, to train, to direct and to guide. Therefore, the role of teachers should be transformed into an excellent designer, a patient coach, an outstanding director, and a fascinating tour guide. All of the new roles require teachers to challenge themselves and to work harder than before. Teachers' new roles require teachers to possess the craftsman spirit without which one may not be successful in the process of the transformation of their roles. With the reconstruction of teachers' roles, they will demonstrate their craftsman spirit with which they could take great delight in transforming their roles for the long term development of students and for the cultivation of students ability.

\section{ACKNOWLEDGMENT}

This paper is assisted by many teachers and students without whom the successful completion of this paper is impossible. Besides, this paper is funded by the Information Center of the Minister of Education on the Mixed classroom learning and teaching program(EIJYB2017-016) .

\section{REFERENCES}

[1] Chen Baosheng. The cultivation of technical Talents between the cooperation of higher and vocational Education[N] China Daily, 2018:19

[2] The Minster of Higher Education. College English Teaching Requirement[M]. Beijing, Tsinghua University, 2017:33

[3] Gu Mingyuan. The Explanation of the National Medium and Long term development program (2010-2010)[M]. Beijing Normal University, 2010:22-24

[4] Jacques Delors. Learning: The Treasure within [M]. Education and Science, 2001:08

[5] Liang Chen. The Transmission of Chinese Culture. Foreign Language Research and Teaching [M], 2018

[6] M. Young, Guide to The Technical Talents. Mill Valley, CA: Arts, 2012 